\title{
Hotels
}

\section{Latest developments in Europe's extended-stay sector}

Recerved: 26 July 2005

\section{Riikka Moreau}

is a consultant and valuation analyst with HVS International's London office. Riikka has several years' operational and sales experience in Finland, France and the UK. She holds an MBA from IMHI (Essec Business School, France, and Cornell University, USA) and a BBA in hospitality management from the Haaga Institute in Helsinki. Since joining HVS International, Riikka has advised on a number of hotel investment projects and related assignments in Europe and Africa.

\section{Kristin Thorsteinsdottir}

is a research analyst with HVS International's London office. She joined HVS in September 2004 having gained an MSc in international hotel and tourism management from Oxford Brookes University and a bachelor degree in hotel management from Stavanger University in Norway.

\section{Abstract \\ The extended-stay sector in Europe has traditionally been characterised by fragmented ownership and wide variances in quality. Unlike other sectors of the hotel industry, extended stay has almost no branding. The sector in Europe seems to have evolved as a concept on its own without requiring any significant involvement from international hotel companies. Recent developments, however, indicate that greater consolidation is about to take place in this sector, as some of the largest players in the hotel industry have entered the market, introducing brands that are already established and successful in the USA.}

\section{Keywords: \\ extended stay, hotel, Europe, branding}

Kristın Thorsteinsdottır HVS International 14 Hallam Street London WiW 6JG, UK

Tel: +44 (o) 2078787715 E-mail:

kthorsteinsdottir@hvsinternatıonal.com

\section{OVERVIEW OF THE EUROPEAN EXTENDED-STAY SECTOR}

'Extended stay' has been defined as a stay of five consecutive nights or more. Demand is generated mostly by local companies needing temporary accommodation for their employees or visitors, due to relocation, training or special projects. Some demand comes from insurance companies rehousing people after a fire or other domestic catastrophe; and from leisure travellers, expatriates and those visiting friends or relatives for extended periods. Rooms and amenities in extended-stay properties are oriented towards 
providing a more residential atmosphere than that found in conventional hotels: large living areas, kitchenettes or even fully equipped kitchens are provided. The service component is usually limited to reception, breakfast, laundry and apartment cleaning.

Extended-stay properties in Europe are generally divided into two main categories: apartment hotels and serviced apartments. The main difference between the two is that some of the serviced apartments require the guest to sign a lease for a certain minimum period and provide only a limited service, if any. The terminology and definitions vary and the actual difference between the two is marginal. Currently, the extended-stay segment is dominated by independently owned and managed properties that are typically small in size. Extended-stay hotels, on the other hand, do not normally require a minimum length of stay; however, these properties normally operate with a tiered discount structure based on length of stay. This paper will focus on the apartment hotel, which is also known as the extended-stay hotel, segment.

While little information on the performance of extended-stay hotels in Europe is available, figures from the Highland Group, a consulting firm specialising in extended-stay properties in the USA, demonstrate a solid performance by extended-stay hotels in the USA. ${ }^{1}$ The effects of the recent economic downturn struck this sector at a later stage than the rest of the US hotel industry. Consequently, while the hotel industry as a whole has recovered, full recovery in the US extended-stay hotel sector has yet to be seen. Smith Travel Research reported a 4 per cent increase in average daily rate (ADR) across the US hotel industry in 2004. ADR across extended-stay hotels was up 3.2 per cent after two consecutive years of decline. RevPAR (revenue per available room) of the extended-stay hotels increased by 5.8 per cent in 2004 compared to an increase of 7.8 per cent across the US hotel industry. ${ }^{2}$ But extended-stay hotels continue to generate gross operating profit (GOP) higher than the industry average, with midpriced extended-stay hotels achieving GOP of 47 per cent compared to an average GOP of 43 per cent across the US hotel industry as a whole. This is without doubt one of the most important factors contributing to the popularity of extended-stay hotels among developers and owners, as the compound annual growth in the US extended-stay supply was in the region of 9 per cent from 1998 to 2004 , according to figures provided by the Highland Group. ${ }^{3}$

In the USA extended-stay accommodation was adopted early by the hotel industry as an addition to hotel accommodation, whereas in Europe the sector grew to become a separate concept which until recently has had little involvement from the large players in the industry. Most of the extended-stay properties are still independently owned and operated, with the exception of the Citadines brand, owned by the Ascott Group, an international serviced residence company with over 14,000 units in the key cities of Europe, Asia Pacific and the Gulf. The group has been operating 
since the 1980s and opened the first branded mid-market extendedstay hotel in Europe. The market is dominated by relatively small local players and is markedly heterogeneous, with wide variances in size and quality. This combination of geographically diverse markets and predominantly individual ownership has resulted in a very fragmented sector that has been difficult to qualify or quantify.

The greater space they offer a guest is not the only advantage extended-stay hotels have over conventional hotels; such properties have benefits for the owner and operator too. With more spacious rooms and cooking facilities, extended-stay hotels are often better value for money for the guest, even though they might not necessarily be cheaper than a stay in a hotel. The advantages for the owner or operator are the longer average length of stay, which reduces variable costs, the limited services and F\&B (food and beverage) operations and the simpler front-office structure; all of which lead to lower fixed-cost requirements and thus contribute to higher profit margins. Larger hotel operators benefit from economies of scale, which help to reduce overhead costs even further, and additionally they bring with them management skills acquired from the conventional hotel market.

\section{KEY PLAYERS AND CURRENT DEVELOPMENT ACTIVITY IN EUROPE}

As described above, the extended-stay market traditionally has been dominated by independent owners. In recent years two Asian serviced apartment operators have entered the European market. Ascott operates serviced apartments in London and via the Citadines brand in continental Europe, while Fraser Place has properties in London, Paris and Glasgow. Furthermore, Marriott entered the extended-stay sector with its Executive Apartments and is currently present in Budapest, Brussels, Prague and, most recently, London. The product characteristics and the pricing policy position Marriott's Executive Apartments at the higher end of the market. From information received from Marriott, it is understood that the chain is not at the moment actively looking to introduce Executive Apartments into new markets in Europe. Other key hotel companies, on the other hand, which are exploring opportunities in the extended-stay segment are listed below.

\section{Accor - Suitehotel}

Olivier Devys, chairman and founder of Accor's Suitehotel, prefers to define the brand as a mid-stay product rather than pure extended stay. Having witnessed the success of similar products in the USA, Accor began work on the development of Suitehotel in 1998, with the first property opening at Lille Airport in November 1999. Since then the network has expanded to include 18 hotels, with five of them opening this year: in France, Germany, Austria and Switzerland. The majority of the hotels are owned by Accor, except for the Suitehotels in Nancy and Montpellier, which are franchised, 
and the one in Geneva, which will be run on a management contract. Suitehotel will continue to expand through franchising, first within France and then in European gateway cities such as London, Amsterdam and Barcelona. Mr Devys hopes to grow the Suitehotel network to 70 hotels by the end of 2009. Suitehotel achieved an average occupancy of 60 per cent in 2004, similar to Accor's other mid-market hotel brands Novotel and Mercure, with an average stay of five nights. The target for 2005 is to increase occupancy by 8 per cent.

Mr Devys is optimistic about the future of extended-stay hotels operating in the mid-market segment and describes their prospects as very promising. At this stage there are no plans for Accor to expand into other segments of the market with another extendedstay product.

\section{InterContinental Hotels Group - Staybridge Suites}

InterContinental Hotels Group launched its extended-stay brand in Europe earlier this year. Staybridge Suites is a four-star product which has been highly successful in the USA. A typical Staybridge Suites property is in a central location with easy access to major demand generators. It offers a choice of generous studio or onebedroom suites equipped with a fully fitted kitchen and limited public areas which are focused on a hub kitchen used for both breakfast and evening gatherings. The first Staybridge Suites hotel is expected to open in the UK in 2007 and the brand is expected to expand rapidly in the UK. Brand manager Marc Henriksen stated that once the brand is well established in the UK, InterContinental will start looking for opportunities in mainland Europe.

\section{PERFORMANCE OF AN EXTENDED-STAY HOTEL VERSUS A CONVENTIONAL HOTEL}

This hypothetical example illustrates differences in profitability between a traditional hotel and an extended-stay hotel. In this example the traditional hotel and the extended-stay hotel are assumed to be in a similar location and of a similar size (100 rooms) and standard, to achieve 75 per cent occupancy, an average rate of $€ 100$ and a double-occupancy factor of 1.3 . The resulting revenue is the same in each scenario. A typical length of stay for the conventional city-centre hotel is two nights, however, whereas the average length of stay in an extended-stay property is ten nights. This clearly indicates that the conventional hotel receives five times the number of arrivals of the extended-stay hotel. Logically the marketing costs tend to be lower, as the reservations volume needed to fill the hotel is only one-fifth of that needed in a traditional hotel. The costs relating to the arrivals, namely payroll and variable costs of check-in, housekeeping and maintenance, are lower in an extended-stay property than they are in a traditional hotel. In addition the supporting facilities, ie public areas and F\&B outlets, are limited, thus further decreasing the costs involved. 
Table I: Performance of an extended-stay versus a conventıonal hotel

\begin{tabular}{lcc}
\hline & Hotel & Extended stay \\
\hline Number of units & 100 & 100 \\
Occupancy & $75 \%$ & $75 \%$ \\
Average rate $(€)$ & 100 & 100 \\
Room nights sold & 27,375 & 27,375 \\
Bednights & 35,588 & 35,588 \\
Length of stay & 2 days & 10 days \\
Number of check-ins & 17,794 & 3,559 \\
GOP & $45 \%$ & $65 \%$ \\
\hline
\end{tabular}

Source: HVS International research

Therefore the extended-stay property can achieve a GOP that is 40 per cent higher than that of a conventional hotel (Table 1).

It should be noted that the majority of extended-stay hotels do accept guests for short periods, and the secret of success appears to be achieving the right balance between the short-stay and long-stay segments. Stays of seven nights or less are normally sold at close to rack rates, while the majority of extended-stay hotels offer discounted rates for longer stays. An average discount for a stay of more than seven nights is at least 10 per cent and for stays of more than 28 nights it is 20 per cent. While the shorter-stay segment helps to increase average rates, it also increases the costs.

\section{ISSUES}

The European extended-stay market is still very young in comparison to the US market. Distances between cities in Europe are shorter than they are in the USA, which results in less demand for extended-stay properties. The land available for development in Europe is more scarce than it is in the USA, and therefore more expensive. Extended-stay properties tend to have larger room sizes than traditional hotels and thereby the land cost issue becomes more acute. Extended-stay hotel operators typically position their properties above conventional hotels of similar standard in the vicinity, seeking a bonus based on the enhanced in-room facilities. But many guests perceive extended-stay properties to be somewhat lower in quality, maybe because of the limited services provided, and therefore expect them to be cheaper than local hotels. Some upscale operators have found the gap between the perceived value and budgeted rates needed to guarantee the necessary return on investment challenging. But the mid-scale properties appear to have found a gap in the market and are performing very well. In any case, taking into consideration the relatively new extended-stay market in Europe, it remains to be seen how quickly demand will grow and how soon developers become convinced of the opportunities in the market for extended-stay hotels.

\section{CONCLUSION}

The extended-stay segment was developed to complement the hotel market in the USA. Today it is established and can be highly 
profitable to the owner. In Europe the extended-stay market has been dominated by independently owned and operated units, mostly serviced apartments, and no data have been systematically gathered to illustrate their performance in comparison to conventional hotels. Extended-stay hotels in recent years have been the focus of interest for large hotel chains, which have explored opportunities around Europe. Extended-stay hotels provide limited services and tend to have longer lengths of stay than conventional hotels, and therefore lower operating costs and increased profitability. Hotel companies seem to agree on the opportunities in mid-market extended-stay hotels in primary and many secondary European cities. But, at the moment, up-market extended-stay hotels are experiencing difficult trading conditions; they face stiff competition not only from upscale hotels, often with similar prices and more extensive services, but also from upscale serviced apartments that are already better established in the market. It will be interesting to see how the extended-stay hotel market develops over the next few years ande how the market reacts to the new concept.

\section{References}

1. Highland Group (2005) The 2005 US Extended Stay Lodging Market. Highland Group, Atlanta, GA

2 Ibid

3 Ibid 